\title{
Epidermal growth factor receptor (EGFR) expression and mutations in the EGFR signaling pathway in correlation with anti-EGFR therapy in head and neck squamous cell carcinomas
}

\author{
P. SMILEK ${ }^{1, *}$, J. NEUWIRTHOVA ${ }^{1}$, J. JARKOVSKY ${ }^{3}$, L. DUSEK ${ }^{3}$, J. ROTTENBERG ${ }^{1}$, R. KOSTRICA ${ }^{1}$, J. SROVNAL ${ }^{2}$, M. HAJDUCH ${ }^{2}$, J. DRABEK ${ }^{2}$, J. KLOZAR ${ }^{4}$ \\ ${ }^{1}$ Department of Otorhinolaryngology and Head and Neck Surgery, Masaryk University and St. Anne's Faculty Hospital Brno, Czech Republic; \\ ${ }^{2}$ Laboratory of Experimental Medicine, Institute of Molecular and Translational Medicine, Palacky University and Faculty Hospital Olomouc, \\ Czech Republic; ${ }^{3}$ Institute for Biostatistics and Analyses, Faculty of Medicine, Masaryk University, Brno, Czech Republic; ${ }^{4}$ Department of Otorhi- \\ nolaryngology and Head and Neck Surgery, First Faculty of Medicine, Charles University, Prague, Czech Republic
}

*Correspondence: smilek@med.muni.cz

Received January 31, 2012 / Accepted March 22, 2012

\begin{abstract}
Epidermal growth factor receptor (EGFR) is an important therapeutic target and a poor prognosis factor in head and neck squamous cell carcinoma (HNSCC). The aim of the study was to analyze EGFR expression and KRAS and EGFR mutational status and to correlate it with treatment response to anti-EGFR therapy combined with radiotherapy in 29 patients with advanced head and neck squamous cell carcinomas (HNSCC).

EGFR gene expression normalized to GAPDH and EGFR variant type III (EGFRvIII) was detected in tumor tissue using real time reverse transcription -PCR. The mutational status of the EGFR and KRAS genes was investigated by real time PCR with sequence specific primers.

Gene expression median values were $3.1 \times 10^{8} \mathrm{GAPDH}$ gene copies per $\mu \mathrm{g}$ of RNA, and $8 \times 10^{6}$ EGFR gene copies per $\mu \mathrm{g}$ of RNA. The median EGFR/GADPH ratio reached 0.14. Patients, who achieved complete response after Cetuximab combined with radiotherapy, had significantly higher expression of the EGFR gene in tumors than patients with partial remission or patient without treatment response. An EGFRvIII mutation was found in $20.7 \%$ of patients and no association was found between this mutation and treatment response. 27 patients (93.1\%) had an EGFR gene wild type tumor, and deletion in exon 19 was found in two patients with a poor clinical outcome. Most of the patients (82.8\%) had a KRAS wild type tumor; a p.Gly12Cys was found in three patients and a p.Gly12Val mutation in one. Presence of a p.Gly12Val mutation in the KRAS gene was associated with an absence of response to treatment.

Conclusion: Our data suggest that KRAS mutation (p.Gly12Val) and somatic EGFR mutation located in exon 19 may contribute to the limited clinical response to therapy with cetuximab + radiotherapy. Higher EGFR gene expression serves as an independent indicator of good clinical response to EGFR-targeted therapy + radiotherapy.
\end{abstract}

Key words: HNSCC, EGFR, KRAS, EGFR gene expression

In the treatment of head and neck squamous cell carcinomas nowadays we can see a worldwide effort to prolong survival with a satisfactory quality of life. This requires

\footnotetext{
Abbreviations: HNSCC - head and neck squamous cell cancer; EGFR (HER1, c-erb B1) - epidermal growth factor receptor; RT-PCR- reverse transcriptase polymerase chain reaction; KRAS - oncoprotein, encoded by the KRAS gene, intracellular transducer in the EGFR signal transduction pathway; OS - overall survival; EFS- event-free survival (time to recurrence or progression or death); FISH - fluorescent in situ hybridization; GAPDH - housekeeping gene (Glyceraldehyde 3-phosphate dehydrogenase) is control gen serving for normalization of expression.
}

earlier detection of disease and also new treatment strategies - new chemotherapeutic regimens, intensity-modulated radiotherapy, and targeted treatment. The latter is especially promising when combined with radiotherapy. Monoclonal antibody against epidermal growth factor receptor (EGFR) demonstrated good antitumor activity in the first line treatment of locally advanced head and neck cancers[1]. EGFR (HER1, c-erb B1) is a member of the receptors family. It is a well -characterizedproto-oncogene that is present in many cancer site where itpromotes tumor progression. It comprises an extracellular ligand-binding domain, a transmembrane 
region, and an intracellular domain which includes a kinase domain and autophosphorylation sites. EGFR is ubiquitouslydistributed in normal epithelial tissues and is over-expressed in a wide range of cancers; in HNSCC approximately in 80 $\%[2,3]$. EGFR plays a critical role in the control of cellular proliferation, differentiation and survival. The binding of ligand to the EGFR triggers EGFR homodimerisation or heterodimerisation of the EGFR with another receptor from its family, results in autophosphorylation and downstream signaling [4]. Genetic abnormalities in the EGFR signaling pathway in HNSCC were not yet sufficiently described. The effect of EGFR inhibitors depends on the presence of genetic alteration in the EGFR signaling pathway [5-7]. Therefore it is necessary to seek markers of response to this therapy at the level of an individual genetic profile. Predicting the outcome in EGFR-targeted therapies is complex and involves genetic and clinical characteristics. In addition to the predictive value of non-smoking, and the higher intensity of skin reaction [8], predictive markers appear to exist at the level of specific genetic aberrations causing deregulation of the cell cycle. The influence of the tyrosinkinase domain of EGFR on positive response to the treatment with extracellular inhibitors has not been elucidated yet $[9,10]$. Constitutive activation of intracellular transducers in the EGFR signaling pathway (KRAS mutation or STAT-3 mutation), loss of the extracellular EGFR inhibitor binding site (EGFRvIII mutation), activation of EGFR-independent tumor angiogenesis (overexpression of VEGF) or altered activation of alternative tyrosinkinase receptors are among promising negative predictors [11]. In many studies, resistance to extra- and intracellular inhibitors was proven during continuous activation of the MAPK pathway [11-13]. In this context, a presence of activating KRAS mutation, which is typical of smokers, has a negative predictive value in various types of tumors, e.g. colorectal cancer[14, 15, 18]. EGFRvIII mutation (EGFR variant with deletion in exons 2-7) is found only in tumor cells. Such a mutated receptor lacks an extracellular domain; therefore extracellular inhibitors cannot bind to it. However, EGFRvIII is able to dimerize even without constitutive activation by ligand binding, and its moderate degree of auto-phosphorylation is sufficient for activation of the signaling pathway but insufficient for induction of its internalization (and down-regulation).

The aim of the present study was to analyze EGFR gene expression, and EGFR and KRAS mutational status in the correlation with treatment response to targeted therapy combined with radiotherapy in patients with advanced HNSCC.

\section{Patients and methods}

Patients.A prospective clinical study include 83 patients with verified locoregional advanced HNSCC. 29 patients were Cetuximab-treated in two tertiary centers. Remaining 54 patients were screened, and the sample for genetic analysis was taken, but Cetuximab treatment was not started due to not fulfilling inclusion criteria $(n=36)$ or noncompliance $(n=4)$ or for organizational reasons $(n=10)$ or for allergic reaction $(n=4)$. Inclusion criteria comprised a good general condition without allergy (ECOG 0,1), age up to 65 years, absence of serious

\section{Overall survival $(\mathrm{N}=29)$}

\section{Event free survival $(\mathrm{N}=29)$}
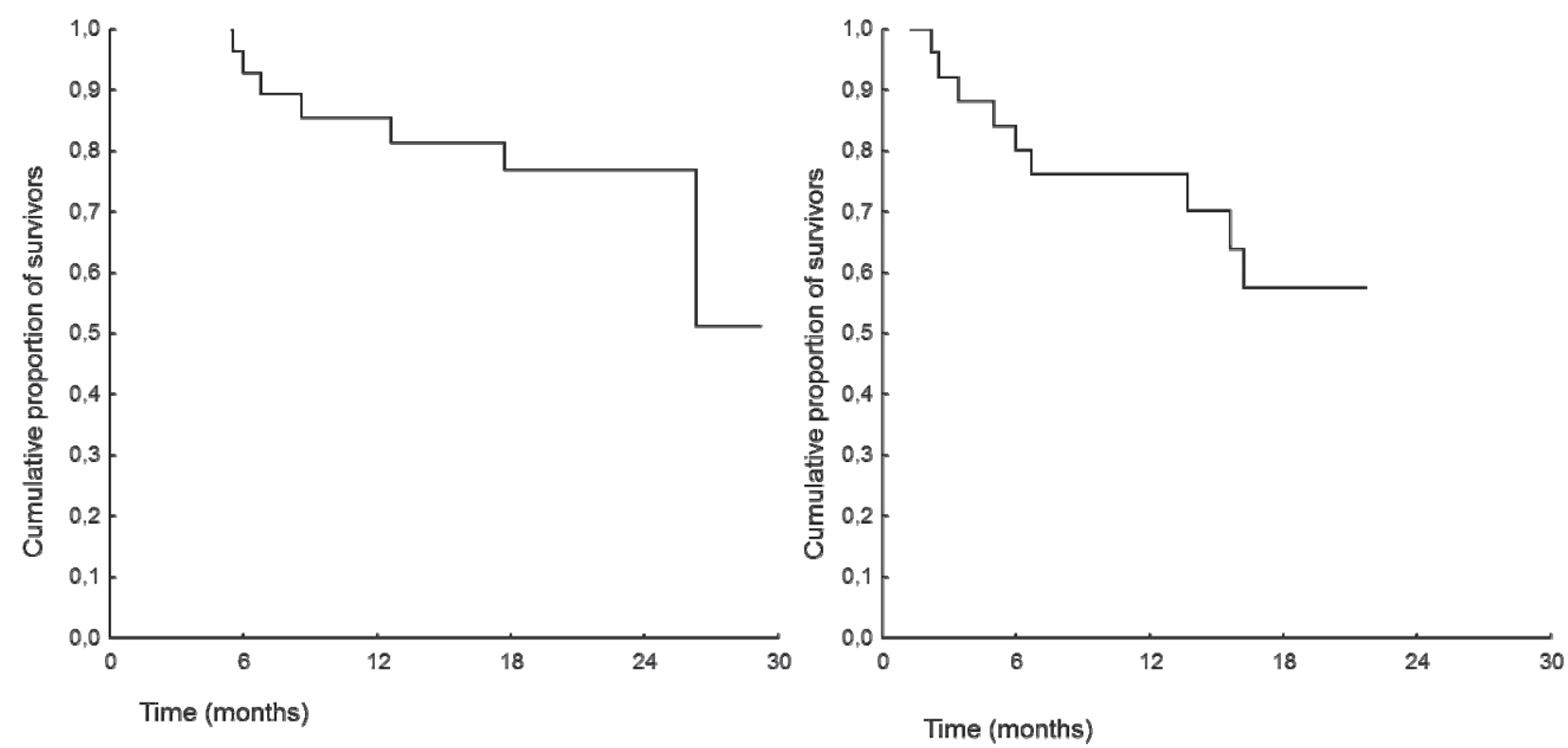

Figure 1. Survival end-points in Kaplan-Meier analysis (patients in stage 3+4, N=29) 
Table 1 Characteristics of the patient population

\begin{tabular}{lrc}
\hline & & Description \\
\hline Sex & Male & $24(82.8 \%)$ \\
& Female & $5(17.2 \%)$ \\
\hline Age & 55 years $\leq$ & $14(48.3 \%)$ \\
& 55 years $>$ & $15(51.7 \%)$ \\
\hline
\end{tabular}

Site

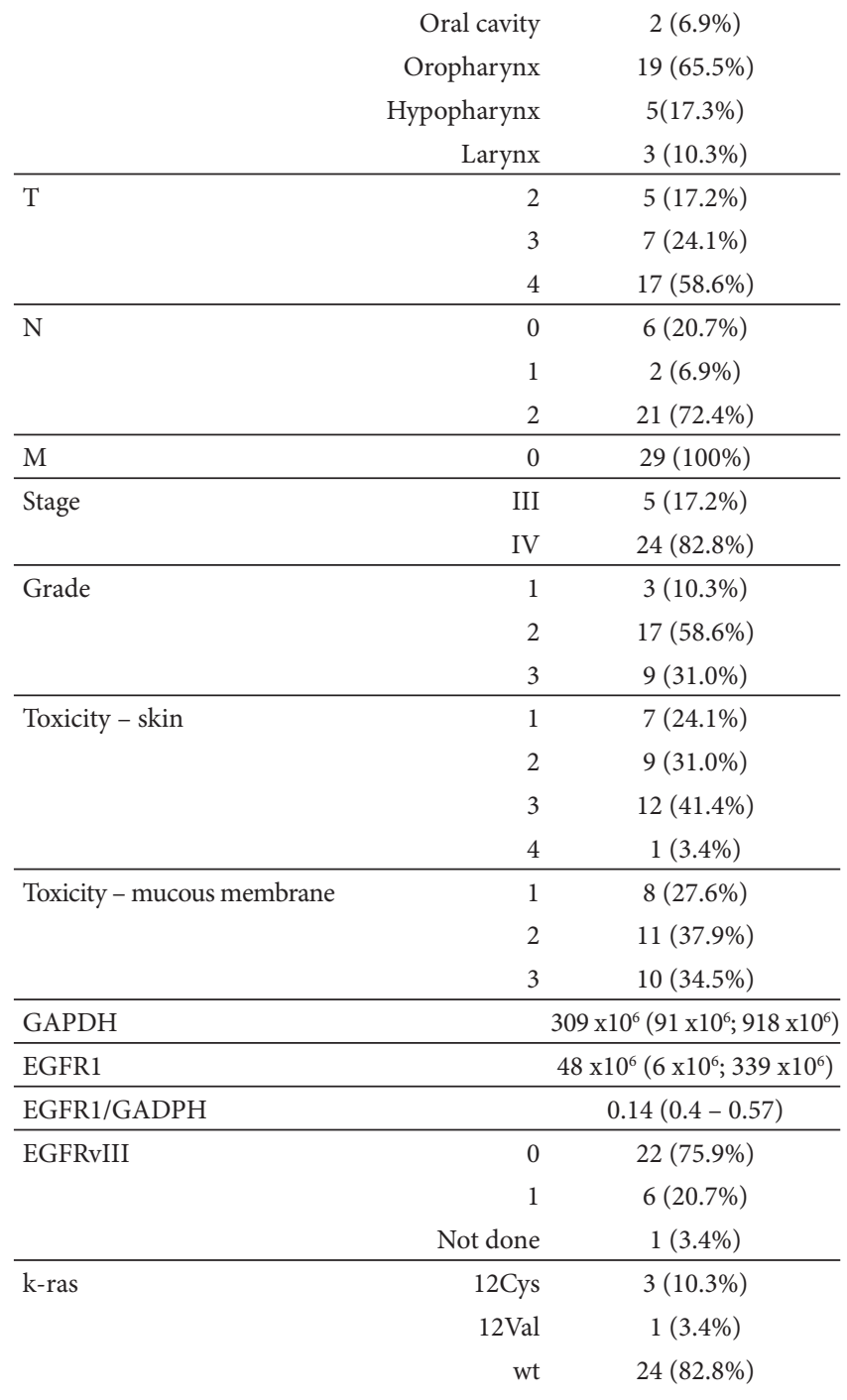

\begin{tabular}{lrc} 
Not done & $1(3.4 \%)$ \\
\hline EGFR & Deletion in exon & $2(6.9 \%)$ \\
19 & $27(93.1 \%)$ \\
\hline Any mutation & No & $22(78.6 \%)$ \\
& Yes & $6(21.4 \%)$
\end{tabular}

Legend to Table 1.Absolute and relative frequencies were used to describe categorical data; a median with the $5^{\text {th }}-95^{\text {th }}$ percentile range was adopted for continuous parameters.

GAPDH (housekeeping gene Glyceraldehyde 3-phosphate dehydrogenase) is control gen serving for normalization of expression. Number in GAPDH and EGFR mean degree of expression;it means how many copies are present in $1 \mu \mathrm{g}$ mRNA acquired from tumor sample. intercurrent diseases, signing of the informed consent form, and weight loss under $10 \%$. The study was approved by the Ethics committee of the St. Anne Faculty Hospital. The patients were treated with radiotherapy (70 Gy) with concomitant 8week intravenous administration of Cetuximab. The patients characteristics are presented in Table 1.

Methods. The recorded data were age, gender, tumor location, TNM classification, histopathological grading, therapeutic response, toxicity according to $\mathrm{WHO}$, event-free survival (EFS - interval between treatment and relapse or progression of the disease) and overall survival (OS). Tumor samples were taken before treatment mostly from peripheral active parts of tumors and were fixed in RNA Later (Qiagen) and frozen. EGFR and GAPDH gene expressions and EGFRvIII mutations were detected in RNA by the RT-PCR method [16, 17]. Total RNA from RNA Later (Qiagen) fixed tissues were purified by the phenol-chloroform method using TRI Reagent (Molecular Research Center) according to the manufacturer's instructions. For reverse transcription, $3 \mu \mathrm{g}$ of total RNA was pre-incubated with Random Primers (Promega) and then reverse transcribed using RevertAid Moloney Murine Leukemia Virus reverse transcriptase (Fermentas). To amplify cDNA of the epidermal growth factor receptor 1 (EGFR1, NM_005228), epidermal growth factor receptor vIII (EGFRvIII, NM_005228) and glyceraldehyde3-phosphate dehydrogenase (GAPDH, NM_002046) (10), the following set of primers and probes were used: EGFRfw 5'-ACTTCAAAAACTGCACCTCCAT-3', EGFR-rev 5'AATCAGCAAAAACCCTGTGATT-3' and EGFR-probe 5'-ACATCCTGCCGGTGGCATTTAGG-3' BHQ1-HEX (149 bp); EGFRvIII-fw 5'-AGTCGGGCTCTGGAGGAA3', EGFRvIII-rev 5'-GCCGTCTTCCTCCATCTCATA-3' and EGFRvIII-probe 5'-ATCACGGCTCGTGCGTCCG-3' BHQ1-HEX (102 bp); GAPDH-fw 5'- GAAGATGGTGATGGGATTTC-3',GAPDH-rev5'AGTCGGGCTCTGGAGGAA -3 ' and GAPDH-probe 5'-CAAGCTTCCCGTTCTCAGCC -3' BHQ1-FAM (226 bp) (Generi-Biotech).

To analyze the EGFR1, GAPDH and EGFRvIII mRNA copies, a quantitative real-time polymerase chain reaction (qPCR) was performed in three $25 \mu \mathrm{l}$ reactions containing $1 \mathrm{U}$ of HotStart Taq Polymerase, $3 \mathrm{mM} \mathrm{MgCl}_{2}$, 10x PCR buffer (AB Gene), $200 \mu \mathrm{M}$ dNTPs (Promega), $100 \mathrm{ng}$ of cDNA, and either 400 nM EGFR-fw, 400 nM EGFR-rev, 200 nM EGFR-probe, or 300 nM GAPDH-fw, 300 nM GAPDH-rev, 200 nM GAPDH-probe, or 400 nM EGFRvIIIfw, 400 nM EGFRvIII-rev, 200 nM EGFRvIII-probe and using Rotor Gene 3000 (Corbett Research). The optimized thermal profile for EGFR1 amplification was initiated with 15 -min. polymerase activation at $96^{\circ} \mathrm{C}$, followed by 50 cycles of $95^{\circ} \mathrm{C}$ for $15 \mathrm{~s}$ and $62^{\circ} \mathrm{C}$ for $15 \mathrm{~s}$, for GAPDH amplification 50 cycles of $95^{\circ} \mathrm{C}$ for $15 \mathrm{~s}$ and $60^{\circ} \mathrm{C}$ for $30 \mathrm{~s}$ and for EGFRvIII 50 cycles of $95^{\circ} \mathrm{C}$ for $15 \mathrm{~s}$ and $61^{\circ} \mathrm{C}$ for $12 \mathrm{~s}$. The presence of the truncated EGFRvIII gene was subsequently verified by post-PCR electrophoresis using Agilent 2100 Bioanalyzer DNA chips (Agilent). 
Tumor wild type DNA was extracted using a DNeasy Blood \& Tissue Kit (Qiagen) from RNA Later (Qiagen) fixed tissues. KRAS mutations were detected by the quantitative real-time PCR method using the Amplification Refractory Mutation (ARMS) principle for discrimination and Scorpion primers for visualization: eight $P C R$ reactions from a TheraScreen DxS KRAS kit (QiaGen) were used for detection of the seven most frequent mutations of KRAS gene (codon 12: Ala, Asp, Arg, Cys, Ser, Val and codon 13: Asp). Similarly, EGFR mutations were detected by the quantitative real-time PCR method using a combination of the ARMS principle and PNA clamping for discrimination and an SYBR Green intercalator for visualization: eight PCR reactions from Panagene PNAClamp kit (PentaGen) were used for detection of substitutions G719X in exon 18, 20 types of deletions in exon 19, substitutions S768I and T790M in exon 20, 2 types of insertions in exon 20, and substitutions L858R and L861Q in exon 21. The sensitivity of both kits is $1 \%$ of mutant DNA in background of wild type DNA.

Data analysis.Standard descriptive statistics were used to summarize primary data, i.e. frequency analysis for categorical variables and a median supplied with the $5^{\text {th }}-95^{\text {th }}$ percentile range for continuous variables. Statistical comparison of variants was based on Mann-Whitney $\mathrm{U}$ test in continuous variables and on an ML- $\mathrm{c}^{2}$ test for categorical variables. Standard Kaplan-Meier analysis was used to estimate profiles of survival. Differences among groups of patients in stratified survival analysis were tested using log-rank test. A value $a=0.05$ was accepted as the cut-off for a statistically significant outcome in all applied tests. Analyses were realized using the software SPSS 19.0.1 (IBM Corporation, 2010).

\section{Results}

Patient characteristics. Twenty-nine patients were included in the study -24 men and 5 women. Half of the cohort (14 patients) were under 55 years of age, while 15 patients were over 55 years old. All patients had advanced disease (clinical stage III and IV). Almost $60 \%$ of patients had grade 2 tumor, $31 \%$ grade 3 and $10 \%$ grade 1 (Table 1 ). Tumors were located in the oral cavity (6.9\%), oropharynx (65.5\%), hypopharynx $(17.3 \%)$ and larynx (10.3\%). Five (17.2\%) patients were treated in stage III and $24(82.8 \%)$ in stage IV. Overall survival (OS) and event-free survival (EFS) were assessed: the median follow-up was 21.7 months, the 2-year OS was $75 \%$, and seven patients died (Graph 1). Both survival parameters were also assessed for various types of patient stratification (gender, age, clinical stage, grade, genes activity, and mutations). No statistically significant differences were found however in this analysis. Overall, a good treatment response was recorded during the study. Complete remission was achieved in $80 \%$ of patients, another $10 \%$ had partial remission, and only $10 \%$ of patients did not respond to the treatment. Serious adverse effects (grades 3 and 4 ) associated with toxicity on the skin occurred in $44.8 \%$ of patients, while serious mucosal toxicity was recorded in $34.5 \%$ of patients (Table 1). EGFR expression and KRAS and EGFR mutational status were correlated with treatment response to anti-EGFR therapy combined with radiotherapy (Table 2).

EGFR Gene expression.GAPDH and EGFR gene levels were assessed. Median values were $3.1 \times 10^{8} G A P D H$ gene copies per $\mu \mathrm{g}$ of RNA, $8 \times 10^{6} \mathrm{EGFR}$ gene copies per $\mu \mathrm{g}$ of RNA and 0.14 for the EGFR/GADPH ratio. Treatment results were analyzed in relation to molecular characteristics of patients. Patients who achieved a complete response had significantly higher expression of the EGFR gene than patients with a partial response or without a response (Table 2, $\mathrm{p}=0.02$ ). The relation between treatment result and $E G F R$ gene expression normalized to GAPDH was not statistically confirmed. A statistically significant relationship $(\mathrm{p}<0.05)$ of EGFR/GADPH for mucosal toxicity was found (data not shown).

EGFRvIII mutation analysis.EGFRvIII mutation was found in $20.7 \%$ ( 6 out of 29) patients. The expected significant association between this mutation and treatment response to anti-EGFR therapy (Cetuximab) was not found. No significant difference was found between different clinical characteristics (age, clinical stage, grade, toxicity) and EGFRvIII mutation with the exception of gender (EGFRvIII was not found in women).

EGFR mutation analysis.27 patients (93.1\%) had wildtype EGFR gene; deletion in exon 19 was found in two patients. Presence of EGFR mutation (deletion in exon 19) was associated with a worse prognosis - presence of recurrence and/or progression and/or death (Table 2, $\mathrm{p}=0.033$ ) and with no response to treatment (Table $2, \mathrm{p}=0.042$ ).

KRAS mutation analysis.Most of the patients $(82.8 \%)$ had wild-type KRAS. P.Gly12Cys and p.Gly12Val mutation was found in three patients and one patient, respectively. Presence of p.Gly12Val mutation in the KRAS gene was associated with no response to treatment; this statement is, nevertheless, based on experience with one patient only (Table $2, \mathrm{p}=0.027$ ). In total, one of two mutations tested (deletion in exon 19 and KRAS mutation) was found in 6 patients (Table 1).

No significant difference was found between different clinical characteristics (gender, age, clinical stage, grade, toxicity) and any of these mutations.

\section{Discussion}

The treatment response (CR $80 \%$ ) of radiotherapy combined with Cetuximab in our set of patients is consistent with Bonner's et al. report in which patients have good therapeutical results[1] and with experimental data of Gurtner et al. [18]. The knowledge of EGFR expression and EGFR and KRAS mutational status becomes clinically important with the wider use of anti-EGFR therapies in HNSCC. In our study, patients who achieved a complete response had significantly higher number of EGFR gene mRNA copies than patients wit partial remission only or patients without a treatment response. 


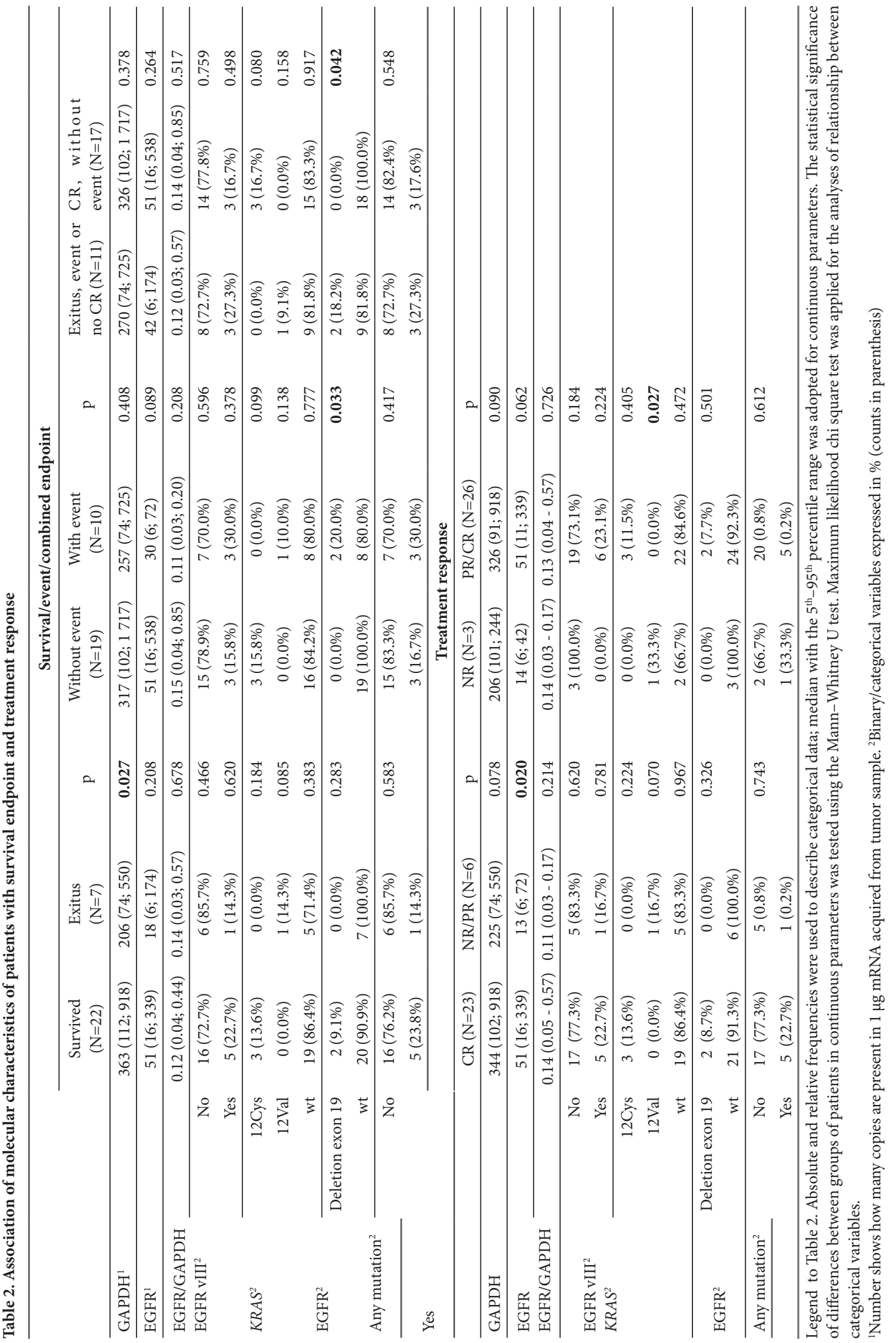


There is experimental evidence that EGFR amplification and elevated EGFR expression levels in HNSCC may result in a less favorable prognosis $[18,20]$, but clinical studies are inconclusive [21]. A high EGFR gene copy number could be a positive predictive marker for treatment response[2, 19]. There are discrepancies between the results of studies comparing the EGFR amplification and the EGFR expression in various tumors: some authors have reported the correlation $[22,23]$ while others have not [24]. The detection of the EGFR expression depends partly on the specificity and sensitivity of available immunohistochemical sets [24]. Furthermore, there are differences of the EGFR expression within a tumor: the highest expression, e.g. the most active parts, can be found in the periphery, whereas in central parts the expression could be very low or negative. FISH has been used as a reference method for the assessment of gene amplification for many years; however, there are several ways to analyze gene expression by FISH $[2,25,26]$ and not all authors distinguish true gene amplifications from chromosomal polysomy. This could be a reason why there are studies with a low percentage of FISH positivity, e.g. 17\% [2], whereas other studies present $58 \%$ [27] or 63\% [19] in HNSCC. In chemotherapy-treated non-small-cell lung cancer patients, the EGFR gene copy number was positively associated with protein level but none of the features were predictive for either treatment response or survival[28]. The amplification of the EGFR gene is the most frequent alteration of glioblastoma multiforme and confers advantages of growth and invasiveness and radio- and chemo resistance on tumor cells. The FISH method is commonly used to determine gene copy numbers, but the quantitative real-time polymerase chain reaction (qPCR) used in our study can obtain a gene copy number, is less expensive, and makes data interpretation more reliable because of use of a large area of tumors [2]. The mutations of the tyrosine kinase domain of the EGFR gene in the exons 19 and 21 are known to affect sensitivity to the EGFR inhibitors; at the same time, they can be used as positive predictive markers during therapy with intracellular inhibitors $[6,29,30]$. Some data suggest that EGFR mutations do not confer sensitivity to the monoclonal antibody Cetuximab. Cetuximab binds to the cell-surface receptor, whereas the kinase inhibitors bind to the intracellular tyrosine kinase domain; therefore in EGFR mutant cell lines Cetuximab has relatively little effect [11].

KRAS mutation (p.Gly12Cys) was found in our study in 3 patients out of $29(10.3 \%)$ and KRAS mutation (p.Gly12Val) was found in one patient out of 29 (3.4\%). KRAS mutation was connected with an absence of response to Cetuximab therapy combined with radiotherapy. KRAS gene mutation is known as a negative prognostic marker [18]. This mutation is strongly associated with a negative response to the EGFR inhibitors and it is used as a negative predictive marker in some types of tumors $[14,31]$. The KRAS gene mutation is rare in HNSCC [32]. Van Damme et al. did not find any KRAS mutation by sequencing in a set of 24 patients with tonsil squamous cell carcinoma. The authors conclude that KRAS mutation analysis is not useful as a screening test for sensitivity to anti-EGFR therapy in tonsil squamous cell carcinoma [26]. Hoa et al. supposed that amplification of wild-type KRAS promotes growth of HNSCC [33].

EGFRvIII has been examined only in a small amount of HNSCC tumors[20]. In our study the rate of EGFRvIII detected at the mRNA level by RT-PCR was $20.7 \%$ (6 out of 29). Sok et al. found EGFRvIII expression established by immunohistochemistry in $42 \%$ of HNSCC tumors (14 out of 33), and in nearly half of HNSCC tumors established by RT-PCR [20]. Ji et al. [34] found EGFRvIII mutation in 5\% (3 out of 56) in squamocellular cancer and not in lung adenocarcinomas. Chau et al.[35] found EGFRvIII mutation in $40 \%$ (22 out of 53) in HNSCC and it appeard to be biomarker associated with better disease control in recurrent or metastatic disease, but no difference was seen between erlotinib-treated versus nonerlotinib treated patients. In our study we could not prove an influence of EGFRvIII on treatment response to EGFR targeted therapy. In HNSCC, resistance to monoclonal antibodies and decreased response to cisplatin was demonstrated in the presence of EGFRvIII [36]. Sok et al. proved that EGFRvIII contributes to enhanced growth and resistance to targeting wild-type EGFR [20].

\section{Conclusions}

Our data suggest that KRAS mutation (p.Gly12Val) and somatic EGFR mutation located in exon 19 may contribute to the limited clinical response to therapy with Cetuximab + radiotherapy. Higher EGFR gene expression serves as an independent indicator of good clinical response to Cetuximab therapy combined with radiotherapy. A correlation between EGFRvIII and clinical response to EGFR targeted treatment was not proven. Our results are limited by the size of the evaluated sample and should be verified on a larger cohort of HNSCC patients.

Acknowledgements: This study was supported by the grant IGA MZCR No. NS 10108-4.

\section{References}

[1] BONNER JA, HARARI PM, GIRALT J, AZARNIA N, SHIN $\mathrm{DM}$ et al. Radiotherapy plus cetuximab for squamous-cell carcinoma of the head and neck. N Engl J Med 2006; 354: 567-678. http://dx.doi.org/10.1056/NEJMoa053422

[2] TEMAM S, KAWAGUCHI H, EL-NAGGAR AK, JELINEK J, TANG $\mathrm{H}$ et al. Epidermal growth factor receptor copy number alterations correlate with poor clinical outcome in patients with head and neck squamous cancer. J Clin Oncol 2007; 25: 2164-2170. http://dx.doi.org/10.1200/JCO.2006.06.6605

[3] EGLOFF AM, GRANDIS JR. Targeting epidermal growth factor receptor and SRC pathways in head and neck cancer. Semin Oncol 2008; 35: 286-297. http://dx.doi.org/10.1053/ j.seminoncol.2008.03.008 
[4] BRAND TM, IIDA M, CHUNRONG L, WHEELER DL. The Nuclear Epidermal Growth Factor Receptor Signaling Network and Its Role in Cancer. Discov Med 2011; 12: 419-432.

[5] SZABO B, NELHUBEL GA, KARPATI A, KENESSEY I, JORI $B$ et al. Clinical significance of genetic alterations and expression of epidermal growth factor receptor (EGFR) in head and neck squamous cell carcinomas. Oral Oncology 2011; 47: 487496. http://dx.doi.org/10.1016/j.oraloncology.2011.03.020

[6] GAZDAR AF. Activating and resistance mutations of EGFR in non-small-cell lung cancer: role in clinical response to EGFR tyrosine kinase inhibitors. Oncogene 2009; 28(Suppl 1): 24-31. http://dx.doi.org/10.1038/onc.2009.198

[7] WHEELER DL, DUNN EF HARARI PM. Understanding resistance to EGFR inhibitors - impact on future treatment strategies. Nature rewiewe Clin Oncol 2010; 7: 493-507.

[8] VINCENZI B, SANTINI D, LOUPAKIS F, ADDEO R, LLIMPE FLR et al. Cigarettes smoking habit may reduce benefit from cetuximab-based treatment in advanced colorectal cancer patients. Expert Opin Biol Ther 2009; 9: 945-949.http://dx.doi. org/10.1517/14712590903081694

[9] MUKOHARA T, ENGELMAN JA, HANNA NH, YEAP BY, KOBAYASHI $S$ et al. Differential effects of gefitinib and cetuximab on non-small cell lung cancers bearing epidermal growth factor receptor mutations. J Nat Cancer Inst 2005; 97: 1185-1194. http://dx.doi.org/10.1093/jnci/dji238

[10] LILENBAUM RC, JOHNSON B, LYNCH T, SANDLER A, BUNN $P$ et al. The evolving role of cetuximab in non-small cell lung cancer. Clin Cancer Res 2006; 12: 4432-4435. http:// dx.doi.org/10.1158/1078-0432.CCR-06-0097

[11] ROSELL R, TARON M, REQUART N, ISLA D, MORAN T. Epidermal Growtht Factor Receptor Activ ation: How Exon 19 and 21 Mutations Changed Our Understanding of the Pathway. Clin Cancer Res 2006; 12: 7222-7230. http://dx.doi. org/10.1158/1078-0432.CCR-06-0627

[12] CHEN L F, COHEN E E, GRANDIS J R. New strategies in head and neck cancer: understanding resistance to epidermal growth factor receptor inhibitors. Clinical Cancer Research 2010; 16: 2489-2495. http://dx.doi.org/10.1158/1078-0432. CCR-09-2318

[13] NIU G, SUN X, CAO Q, COURTER D, KOONG A et al. Cetuximab-based immunotherapy and radioimmunotherapy of head and neck quamous cell carcinoma. Clinical Cancer Research 2010; 16: 2095-2105. http://dx.doi.org/10.1158/ 1078-0432.CCR-09-2495

[14] LIEVRE A, BACHET JB, LE CORRE D, BOIGE V, LANDI $\mathrm{B}$ et al. K-RAS mutation status is predictive of response to cetuximab therapy in colorectal cancer. Cancer Research 2006; 66: 3992-3995. http://dx.doi.org/10.1158/0008-5472. CAN-06-0191

[15] DIFIORE F, BLANCHARD F, CHARBONNIER F, LE PESSOT F, LAMY A et al. Clinical relevance of KRAS mutation detection in metastatic colorectal cancer treated by Cetuximab plus chemotherapy. British Journal of Cancer 2007; 96: 1166-1169. http://dx.doi.org/10.1038/sj.bjc.6603685

[16] RAEJM, SCHEYS JO, CLARK KM, CHADWICK RB, KIEFER $\mathrm{MC}$ et al. EGFR and EGFRvIII expression in primary breast cancer and cell lines. Breast Cancer Res Treat 2004; 87: 87-95. http://dx.doi.org/10.1023/B:BREA.0000041585.26734.f9

[17] TIDOW N, BOECKER A, SCHMIDT H, AGELOPOULOS $\mathrm{K}, \mathrm{BOECKER} \mathrm{W}$ et all. Distinct amplification of an untranslated regulatory sequence in the egfr gene contributes to early steps in breast cancer development. Cancer Res 2003; 63: 1172-1178.

[18] GURTNER K, DEUSE Y, BUTOF R, SCHAAL K, EICHELER W et al. Diverse effects of combined radiotherapy and EGFR inhibition with antibodies or TK inhibitors on local tumour control and correlation with EGFR gene expression. Radiotherapy and Oncology 2011; 99: 323-330. http://dx.doi. org/10.1016/j.radonc.2011.05.035

[19] CHUNG CHH, ELY K, CARTER J, MCGAVRAN L, VARELLA-GARCIA $M$ et al. High gene copy number of epidermal growth factor receptor by fluorescence in situ hybridization is frequent in head and neck squamous cell carcinomas and associates with worse recurrence-free survival. J Clin Oncol 2006; 24 (Suppl 18): 5502.

[20] SOK JC, COPPELLI FM, THOMAS SM, LANGO MN, XI S et al. Mutant epidermal growth factor receptor (EGFRvIII) contributes to head and neck cancer growth and resistance to EGFR targeting. Clinical Cancer Research 2006; 12: 5064 5073. http://dx.doi.org/10.1158/1078-0432.CCR-06-0913

[21] BARBER RD, HARMER DW, COLEMAN RA, CLARK BJL. GAPDH as a housekeeping gene: analysis of GAPDH mRNA expression in a panel of 72 human tissues. Physiol Genomics 2005; 21: 389-395. http://dx.doi.org/10.1152/physiolgenomi cs.00025.2005

[22] SHINOJIMA N, TADA K, SHIRAISHI S, KAMIRYO T, KOCHI M et al. Prognostic value of epidermal growth factor receptor in patients with glioblastoma multiforme. Cancer Res 2003; 63: 6962- 6970.

[23] LEEMANS CR, BRAAKHUIS BJM, BRAKENHOFF RH. The molecular biology of head and neck cancer. Nature Reviews Cancer 2011; 11: 9-22. http://dx.doi.org/10.1038/nrc2982

[24] KERSTING C, PACKEISEN J, LEIDINGER B et al. Pitfalls in immunohistochemical assessment of EGFR expression in soft tissue sarcomas. J Clin Pathol 2006; 59: 585-590. http://dx.doi. org/10.1136/jcp.2005.028373

[25] MORONI M, VERONESE S, BENVENUTI S, MARRAPESE G, SARTORE-BIANCHI A et al. Gene copy number for epidermal growth factor receptor (EGFR) and clinical response to antiEGFR treatment in colorectal cancar: a cohort study. Lancet Oncol 2005; 6: 279-286. http://dx.doi.org/10.1016/ $\underline{\text { S1470-2045(05)70102-9 }}$

[26] VAN DAMME N, DERON P, VAN ROY N, DEMETTER P, BOLS A et al. Epidermal Growth Factor Receptor and K-RAS status in two cohorts of squamous cell carcinomas. BMC Cancer 2010; 10: 189-198. http://dx.doi.org/10.1186/14712407-10-189

[27] CHUNG CHH, ELY K, MCGAVRAN L, VARELLA-GARCIA M, PARKER J et al. Increased Epidermal Growth Factor Receptor Gene Copy Number Is Associated With Poor Prognosis in Head and Neck Squamous Cell Carcinomas. Journal of Clinical Oncology 2006; 24: 4170-4176. http://dx.doi. org/10.1200/JCO.2006.07.2587 
[28] HIRSCH FR, VARELLA-GARCIA M, BUNN PA JR, DI MARIA MV, VEVE R et al. Epidermal growth factor receptor in non-small-cell lung carcinomas: Correlation between gene copy number and protein expression and impact on prognosis. J Clin Oncol 2003; 21: 3798-3807. http://dx.doi. org/10.1200/JCO.2003.11.069

[29] PAEZ JG, JANNE PA, LEE JC, TRACY S, GREULICH H et al. EGFR mutations in lung cancer: correlation with clinical response to gefitinib therapy. Science 2004; 304: 1497-1500. http://dx.doi.org/10.1126/science.1099314

[30] LYNCH TJ, BELL DW, SORDELLA R, GURUBHAGVATULA $\mathrm{S}$, OKIMOTO RA. Activating mutations in the epidermal growth factor receptor underlying responsiveness of nonsmall-cell lung cancer to gefitinib. N Engl J Med 2004; 350: 2129-2139. http://dx.doi.org/10.1056/NEJMoa040938

[31] BISSADA E, ABOU-CHACRA Z, WENG X, GUERTIN P, NGUYEN-TAN M et al. Prevalence of K-RAS codon 12 mutations in locally advanced head and neck squamous cell carcinoma and influence with regards to response to chemoradiation therapy. J Clin Oncol, Meeting Proceedings 2008; 26: Abstr 17008.
[32] SHEIKH ALI MAL, GUNDUZ M, NAGATSUKA H, GUNDUZ E, CENGIZ B et al. Expression and mutation analysis of epidermal growth factor receptor in head and neck squamous cell carcinoma. Cancer Sci 2008; 99: 1589-1594. http://dx.doi. org/10.1111/j.1349-7006.2008.00861.x

[33] HOA M, DAVIS SL, AMES SJ, SPANJAARD RA. Amplification of Wild-Type K-ras Promotes Growth of Head and Neck Squamous Cell Carcinoma. Cancer Res 2002; 62: 7154-7156.

[34] JI H, ZHAO X,YUZA Y, et al. Epidermal growth factor receptor variant III mutations in lung tumorigenesis and sensitivity to tyrosine kinase inhibitors.Proc Natl Acad Sci USA 2006;103: 7817-7822. http://dx.doi.org/10.1073/pnas.0510284103

[35] CHAU NG, PEREZ-ORDONEZ B, ZHANG K, PHAM N, JAMES HO J et al. The association between EGFR variant III, HPV, p16, c-MET, EGFR gene copy number and response to EGFR inhibitors in patients with recurrent or metastatic squamous cell carcinoma of the head and neck. Head \& Neck Oncology 2011; 3: 1-11.

[36] BLAGOSKLONNY, M V. Gefitinib (lressa) in oncogen-adddictive cancers and therapy for common cancers. Cancer Biol Ther 2004; 3: 436-440. http://dx.doi.org/10.4161/cbt.3.5.984 